\title{
Partitioning of reproduction among queens in the Argentine ant, Linepithema humile
}

\author{
DENIS FOURNIER \& LAURENT KELLER \\ Institute of Ecology, University of Lausanne \\ (Received 2 May 2001; initial acceptance 21 June 2001; \\ final acceptance 6 August 2001; MS. number: 6931)
}

\begin{abstract}
We investigated how queens share parentage (skew) in the Argentine ant, Linepithema humile, a social insect with multiple queens (polygyny). Overall, maternity of 546 male and female sexuals that mated successfully was determined with microsatellites in 26 colonies consisting of two queens and workers. The first main finding was that queens all contributed to sexual production. However, there was a significant departure from equal contribution to male and female sexual production in a notable proportion of colonies. Overall, reproductive skew for sexual (male and female) production was relatively low but higher than reproductive skew for egg production. The second interesting result was that there was a trade-off in the relative contribution of queens to male and female production. The queens contributing more to male production contributed significantly less to female sexual production. Finally, there was no significant association between colony productivity and the degree of reproductive skew. The relatively low reproductive skew is in line with predictions of the so-called concession models of reproductive skew because, in the Argentine ant, relatedness between queens is low and ecological constraints on dispersal nonexistent or weak.
\end{abstract}

(C) 2001 The Association for the Study of Animal Behaviour

A key feature differentiating cooperative animal societies is the apportionment of reproduction among individuals (Keller \& Reeve 1994). Societies where all individuals reproduce equally versus societies where a single individual completely monopolizes reproduction only represent end points of a continuum in the variance in the reproductive output among group members. A shorthand term to describe the distribution of direct reproduction among individuals is reproductive skew (Keller \& Reeve 1994). In high-skew societies, actual direct reproduction is concentrated in one or a small subset of individuals in the group; in low-skew societies, reproduction is distributed more evenly among group members.

Building on kin selection theory, a new conceptual framework has recently been developed to determine how ecological, genetic and social factors jointly influence group stability and reproductive skew among group members (Emlen 1982; Vehrencamp 1983a, b; Reeve \& Ratnieks 1993; Keller \& Reeve 1994; Reeve et al. 1998; Johnstone \& Cant 1999; Johnstone 2000; Reeve \& Keller 2001). In essence, skew models delineate the possible reproductive strategies available to a focal individual, and

Correspondence: L. Keller, Institute of Ecology, Bâtiment de Biologie, University of Lausanne, 1015 Lausanne, Switzerland (email: laurent.keller@ie-zea.unil.ch). D. Fournier is now at the Laboratoire de Biologie Animale et Cellulaire, Université Libre de Bruxelles, Belgium. define under what conditions the best option for this individual is to cooperate and/or sacrifice part or all of its direct offspring production rather than leaving the group to breed independently.

The three main parameters important in skew models are: (1) the expected success of a subordinate that reproduces solitarily; (2) the group's overall productivity if the subordinate cooperates; and (3) the genetic relatedness among group members. The effect of these parameters on reproductive skew is expected to vary depending on which group member has control over reproductive skew. Accordingly, three main groups of models have been developed.

The first group of models, the so-called concession models, apply to the situation where the dominant has full control over partitioning of reproduction (Reeve \& Ratnieks 1993). Under this scenario the dominant breeder should yield just enough reproduction to a subordinate to make it favourable for the subordinate to stay in the group and cooperate peacefully rather than to leave the group and reproduce independently or fight to gain exclusive control of the group's resources. The main predictions of concession models is that skew will increase when group productivity increases, ecological constraints on independent breeding increase, and the relatedness between a dominant and a given subordinate is high. 
The second group of models has been developed for the situation where the dominant controls group membership, but the subordinate fully controls the reproductive shares within the group (Johnstone \& Cant 1999). These models are called restraint models because they assume that the subordinate captures the largest share of reproduction that the dominant will tolerate before ejecting the subordinate. In the restraint models, the same parameters are expected to determine reproductive skew but in ways exactly opposite to the concession models.

Finally, the third group of models applies to the situation where both dominants and subordinates have only limited control over the allocation of reproduction within groups, and reproductive sharing simply reflects each group member's inability to monopolize the group's reproduction profitably (Reeve et al. 1998). In the tug-ofwar models (or incomplete control or 'compromise' models), the selfish efforts of individuals to increase their shares of the total group output come at the expense of total group output. These models predict that the subordinate's fraction of reproduction either increases with, or is insensitive to, the subordinate's genetic relatedness to the dominant. Furthermore, the subordinate's share of reproduction should not be influenced by ecological factors affecting solitary breeding success.

The considerable amount of effort that has been devoted to developing reproductive skew models over the last two decades (Vehrencamp 1983a, b; Reeve \& Ratnieks 1993; Keller \& Reeve 1994; Reeve \& Keller 1997; Reeve 1998; Reeve et al. 1998; Johnstone \& Cant 1999; Ragsdale 1999; Johnstone 2000; Reeve \& Emlen 2000) contrasts with the relative paucity of studies testing the assumptions and predictions of these models (Reeve \& Keller 2001). A few studies have tried to determine how variation in relatedness and ecological factors influence skew within species (Bourke \& Heinze 1994; Bourke et al. 1997; Reeve et al. 2000; Clutton-Brock et al. 2001; Reeve \& Keller 2001). There are only two interspecific studies attempting to correlate reproductive skew and relatedness between potential breeders. The first is an intrageneric comparison within the ant genus Leptothorax. In some Leptothorax species, all queens contribute to reproduction (polygyny), whereas in others a single queen monopolizes all of the reproduction (functional monogyny). As predicted by the concession models, the relatedness among nestmate queens is higher in the functionally monogynous species (high skew) than in the five polygynous species (lower skew; Bourke et al. 1997; Reeve et al. 1998). The other study is an intergeneric comparison in four ant species (Linepithema humile, Solenopsis invicta, Leptothorax acervorum and Leptothorax grederli; Reeve et al. 1998). Among these species there is a perfect rank correlation between reproductive skew and genetic relatedness, with skew increasing as relatedness increases.

Taken together, these results are most consistent with high skew being associated with high relatedness in ants. However, caution is necessary for at least four reasons. First, data are available for only a few species and the possibility and extent of asymmetric relatedness between subordinates and dominants, particularly in the functionally monogynous species, has yet to be investigated. Second, there is a negative correlation between queen-queen relatedness and queen number in ants (Keller 1995), so that variation in queen number might be a confounding variable influencing skew independently of relatedness. Third, high relatedness among queens within colonies might be the result of high skew (rather than the cause) when queens are readopted into their native colony (Heinze 1995), as indeed is probably the case in many polygynous ants (Stille \& Stille 1992; Stuart et al. 1993; Keller 1995; Chapuisat et al. 1997; Chapuisat \& Keller 1999). Finally, for almost all these species skew is quantified as the relative contribution of queens to egg production. However, such a measure will be biased if some queens produce eggs that are more likely to develop into female sexuals versus workers (as has been shown in the fire ant, Solenopsis invicta, Ross 1988) or if females produce variable proportions of male eggs (which has never been investigated in polygynous colonies of ants). Hence, studies providing information on the apportionment of reproductives (males and females) in colonies of social insects are badly needed to understand better the evolution of reproductive skew.

Our aim in this study was to determine reproductive skew for male and female sexual production in the Argentine ant, Linepithema humile (previously Iridomyrmex humilis), one of the species that had been used in the intergeneric comparison of skew in ants (Reeve et al. 1998). Skew had previously been quantified on the basis of relative egg production by queens in colonies containing between five and eight queens (Keller 1988). Reproductive skew measured as the relative egg production by queens was low, that is, 0.03 using the skew index of Reeve and Keller (Keller \& Vargo 1993; Reeve \& Ratnieks 1993) which varies from zero (when all breeders contribute equally to the offspring) to one (when there is a single breeder). The low reproductive skew indicates that queens contribute relatively equally to egg production. This finding is consistent with predictions of concession models because relatedness between nestmate queens is low ( $r=0.004$, Reuter et al., in press; this study) and ecological constraints on dispersal are nonexistent or weak (Newell 1909; Markin 1970; Keller \& Passera 1989). However, reproductive skew measured as the relative contribution of queens might not be a good measure of fitness because the majority of the eggs develop into workers that are invariably sterile in this species.

We used eight polymorphic microsatellites (Krieger \& Keller 1999) to determine maternity of male and female sexuals that mated successfully within experimental colonies containing two queens. In this species mating occurs within the nest and individuals do not discriminate between mates on the basis of their relatedness when environmental cues are not available (Keller \& Fournier, in press). That is, sexuals mate randomly with siblings and unrelated individuals within colonies headed by two queens. We also tested whether there is an association between the relative contribution of queens to male and female production and whether reproductive skew is associated with overall colony productivity. 


\section{METHODS}

\section{Field Collections and Breeding Experiments}

We collected colonies of L. humile in Port-Leucate, near Perpignan, southern France on 1 and 2 March 1999 to set up 120 nests each with two queens, 300 workers but no eggs or brood. Queens in the nests were assumed to be unrelated (or only distantly related) as the average relatedness between nestmate queens is low in this population ( $r=0.004$, M. Reuter, F. Balloux, L. Lehman \& L. Keller, unpublished data), which was confirmed by genetic analyses (see below). Colonies were maintained in the laboratory under standard laboratory conditions (Keller \& Passera 1992, 1993). To ensure that colonies contained only brood from the two queens, we checked them regularly for the first 2 weeks and removed any brood. After another 2 weeks we removed the two queens and froze them at $-20^{\circ} \mathrm{C}$ for genetic analyses. The workers then reared the brood that had been produced in the previous 2 weeks. Queenless colonies generally rear male and female sexuals which typically mate in the nest (Keller \& Passera 1992, 1993). We collected all female reproductives that shed their wings, a behaviour generally associated with mating (Passera \& Keller 1992), and stored them at $-20^{\circ} \mathrm{C}$ for genetic analyses. These females and the sperm in their spermathecae were genotyped at the informative loci (inferred from the genotype of their mothers and fathers) to determine which of the two mother queens produced the males and females that mated successfully. In 30 of the 120 colonies the two mother queens and their mate (i.e. sperm in their spermatheca) had genotypes that allowed unambiguous maternity assignment of all their offspring (see below). Of these 30 colonies, 26 produced at least five female sexuals that mated successfully. We used these 26 colonies to determine reproductive skew. The skew was thus determined from the female sexuals that mated successfully and their mates (as determined from the sperm genotype). Maternity was assigned for a total of 273 male and 273 female offspring in these colonies $(\bar{X} \pm \mathrm{SD}=10.6 \pm 0.1$ per colony).

We used binomial tests to determine whether queens differed in their relative contribution to the production of male and female sexuals (two-tailed tests with a probability value of 0.5 ). Because we conducted comparisons across 26 colonies the tests were corrected for multiple comparisons with Bonferroni adjustments (Rice 1989).

To quantify reproductive skew we used the same index $S$ that had previously been used to quantify skew in egg production in several ant species (Bourke \& Franks 1995). This index is equal to

$$
S=\frac{N_{\mathrm{b}} v+N_{\mathrm{n}}}{N_{\mathrm{b}}+N_{\mathrm{n}}}
$$

where $N_{\mathrm{b}}$ is the number of breeders in the colony, $N_{\mathrm{n}}$ is the number of nonbreeders in the colony and $v$ a measure of variation in reproduction among breeders

$$
v=\frac{\frac{\Sigma\left(p_{i}-1 / N_{\mathrm{b}}\right)^{2}}{N_{\mathrm{b}}-1}}{1 / N_{\mathrm{b}}}
$$

with $p_{i}$ being the proportional contribution of offspring by the ith breeder to the total number of offspring. As mentioned earlier, this index varies from zero when all breeders contribute equally to the offspring to one when there is a single breeder.

This index, like most indices used to quantify reproductive skew, is sensitive to sampling errors (Tsuji \& Tsuji 1998; Kokko et al. 1999), that is, the expected value is higher than 0 even when reproduction is shared equally by breeders when there is a finite number of broods. To determine whether differential contribution of queens to brood production was greater than expected under the hypothesis of equal fertility, we generated for each colony an expected skew value assuming that each queen was equally likely to produce each offspring (10000 simulations per colony; Keller \& Krieger's 1996 program available on request). We then compared the expected and observed skew for each colony. Because observed skew values were not always normally distributed (Kolmogorov-Smirnov tests) we used the Wilcoxon signed-ranks test to determine whether the observed skew differed from the expected skew across colonies (Sokal \& Rohlf 1995). We also used the expected skew to generate, for each colony, a corrected skew as proposed by Keller \& Krieger (1996):

$$
s k e w_{\text {corrected }}=\frac{s k e w_{\text {observed }}-s k e w_{\text {expected }}}{s k e w_{\text {maximum }}-s k e w_{\text {expected }}}
$$

This corrected skew was used to compare the skew for sexual production with previous data on skew for egg production (Keller 1988). The use of the corrected skew allowed us to control for differences in the magnitude of sampling errors because more eggs were produced by queens in Keller's study than sexuals in our study.

We used another skew index $(B)$ that combines the observed and expected variances (Nonacs 2000) to determine whether our conclusions were modified. The $B$ index is scaled such that skew values can be affected by different productivities across groups. To control for productivity differences, positive $B$ values need to be divided by $1-1 / N+(1 / N-1) / K$, where $N$ is the number of queens (in our case 2 ), and $K$ the number of offspring (Nonacs 2000). Negative values of $B$ need to be divided by $(1 / N-1) / K$. Analyses performed with this modified version of $B$ (P. Nonacs, personal communication), which varies between -1 and 1 , gave similar results to the other skew indices except for the effects of group size and productivity. We therefore present the results of the analyses with both indices for the relationship between skew and productivity.

All statistical tests are two tailed.

\section{Genetic Analyses}

The two mother queens of each colony and the sperm stored in their spermathecae were genotyped at eight microsatellite loci (Lhum-11, Lhum-13, Lhum-19, 
Table 1. Contribution of queens to the production of females, males and all sexuals

\begin{tabular}{|c|c|c|c|c|c|c|c|c|c|}
\hline \multirow[b]{3}{*}{ Colonies } & \multicolumn{6}{|c|}{ Number of individuals produced by } & \multicolumn{3}{|c|}{$\begin{array}{l}\text { Binomial test } \\
\text { (null hypothesis } \mathrm{H}_{\mathrm{o}}: p=q=0.5 \text { ) }\end{array}$} \\
\hline & \multicolumn{3}{|c|}{ Queen A } & \multicolumn{3}{|c|}{ Queen B } & \multirow[t]{2}{*}{ Females } & \multirow[t]{2}{*}{ Males } & \multirow[t]{2}{*}{ Sexuals } \\
\hline & Females $_{A}$ & Males $_{A}$ & Sexuals $_{A}$ & Females $_{B}$ & Males $_{B}$ & Sexuals $_{B}$ & & & \\
\hline 22 & 3 & 6 & 9 & 9 & 6 & 15 & 0.1460 & 1.0000 & 0.3075 \\
\hline 23 & 6 & 3 & 9 & 6 & 9 & 15 & 1.0000 & 0.1460 & 0.3075 \\
\hline 25 & 10 & 4 & 14 & 4 & 10 & 14 & 0.1796 & 0.1796 & 1.0000 \\
\hline 30 & 3 & 1 & 4 & 3 & 5 & 8 & 1.0000 & 0.2188 & 0.3877 \\
\hline 31 & 11 & 5 & 16 & 2 & 8 & 10 & 0.0225 & 0.5811 & 0.3268 \\
\hline 32 & 0 & 3 & 3 & 6 & 3 & 9 & 0.0313 & 1.0000 & 0.1460 \\
\hline 33 & 0 & 3 & 3 & 6 & 3 & 9 & 0.0313 & 1.0000 & 0.1460 \\
\hline 37 & 7 & 4 & 11 & 1 & 4 & 5 & 0.0703 & 1.0000 & 0.2101 \\
\hline 38 & 11 & 7 & 18 & 0 & 4 & 4 & $0.0010^{*}$ & 0.5488 & 0.0043 \\
\hline 40 & 3 & 1 & 4 & 3 & 5 & 8 & 1.0000 & 0.2188 & 0.3877 \\
\hline 41 & 0 & 6 & 6 & 12 & 6 & 18 & 0.0005 & 1.0000 & 0.0227 \\
\hline 44 & 8 & 5 & 13 & 8 & 11 & 19 & 1.0000 & 0.2101 & 0.3768 \\
\hline 48 & 6 & 0 & 6 & 6 & 12 & 18 & 1.0000 & $0.0005^{*}$ & 0.0227 \\
\hline 57 & 8 & 10 & 18 & 2 & 0 & 2 & 0.1094 & $0.0020^{*}$ & $0.0004^{*}$ \\
\hline 60 & 6 & 3 & 9 & 0 & 3 & 3 & 0.0313 & 1.0000 & 0.1460 \\
\hline 66 & 6 & 9 & 15 & 3 & 0 & 3 & 0.5078 & 0.0039 & 0.0075 \\
\hline 79 & 0 & 3 & 3 & 9 & 6 & 15 & $0.0039^{*}$ & 0.5078 & 0.0075 \\
\hline 86 & 15 & 3 & 18 & 0 & 12 & 12 & $0.0001^{*}$ & 0.0352 & 0.3613 \\
\hline 98 & 0 & 3 & 3 & 6 & 3 & 9 & 0.0313 & 1.0000 & 0.1460 \\
\hline 100 & 9 & 0 & 9 & 3 & 12 & 15 & 0.1460 & $0.0005^{*}$ & 0.3075 \\
\hline 104 & 5 & 0 & 5 & 5 & 10 & 15 & 1.0000 & $0.0020^{*}$ & 0.0414 \\
\hline 107 & 7 & 7 & 14 & 4 & 4 & 8 & 0.5488 & 0.5488 & 0.2863 \\
\hline 108 & 6 & 6 & 12 & 3 & 3 & 6 & 0.5078 & 0.5078 & 0.2379 \\
\hline 112 & 3 & 12 & 15 & 12 & 3 & 15 & 0.0352 & 0.0352 & 1.0000 \\
\hline 113 & 8 & 2 & 10 & 4 & 10 & 14 & 0.3877 & 0.0386 & 0.5413 \\
\hline 115 & 6 & 6 & 12 & 9 & 9 & 18 & 0.6072 & 0.6072 & 0.3613 \\
\hline
\end{tabular}

Significant $P$ values are in bold. Those that remain significant after a Bonferroni correction are marked with an asterisk.

Lhum-28, Lhum-35, Lhum-39, Lhum-52, Lhum-62; Krieger \& Keller 1999). DNA was extracted from individual ants by homogenization in extraction buffer $(\mathrm{NaCl} 100 \mathrm{mM}$, Tris$\mathrm{HCl} 50 \mathrm{mM}$, EDTA $1 \mathrm{mM}$, SDS $0.5 \%$, proteinase $\mathrm{K} 200 \mu \mathrm{g} / \mathrm{ml}$ ) followed by digestion for $2 \mathrm{~h}$ at $55^{\circ} \mathrm{C}$ and extraction with an equal volume of phenol/chloroform/isoamyl alcohol. The DNA was precipitated by sodium acetate in ethanol and suspended in $100 \mu \mathrm{l}$ of sterilized water. PCR reactions were carried out in 10- $\mu$ l reaction volumes. To isolate sperm DNA, we dissected the queen's abdomen in distilled water, removed intact spermatheca and placed them in extraction buffer. We then ruptured the spermatheca with forceps and collected the sperm with a micropipette for genetic analysis. Queens of this species mate only once (Krieger \& Keller 2000) which facilitates maternity assignment.

We used the genotypes of queens to determine their relatedness. Average regression relatedness among queens $\left(r_{\mathrm{q}}\right)$ was estimated following the algorithm of Queller \& Goodnight (1989) by using the program Relatedness 5.0.8. The estimated relatedness $\left(r_{\mathrm{q}}=-0.053\right.$, jackknife $\mathrm{SE}=0.087)$ was not significantly different from zero (two-tailed $t$ test: $t_{24}=0.641, N=26, P=0.528$ ).

\section{RESULTS}

In all colonies both queens contributed to the production of sexuals (Table 1). However, binomial tests showed that there was a significant departure from equal contribution to the production of male and female sexuals in several colonies. One queen produced significantly more female sexuals than the other in 10 out of the 26 colonies. The difference remained significant in three of the colonies after Bonferroni adjustments. Similar results were obtained for male production, with a significant departure from the values expected if queens contributed equally to male production in seven colonies. The difference remained significant in four colonies after Bonferroni adjustments. Finally, unequal contribution of queens to overall sexual (male+female) production occurred in seven colonies, the difference remaining significant in one of these colonies after Bonferroni adjustments.

We obtained similar results by computing the reproductive skew values. Mean reproductive skew for the production of female sexuals \pm SD was $0.42 \pm 0.08$, a value significantly higher than the value $(0.11 \pm 0.00)$ expected under equal contribution (Wilcoxon signedranks test: $Z=-2.781, N=26, P=0.005)$. Reproductive skew for males was $0.31 \pm 0.07$, a value also higher, but not significantly so, than the expected value of $0.11 \pm 0.00$ (Wilcoxon signed-ranks test: $Z=-1.791$, $N=26, P=0.073)$. Finally, reproductive skew for overall sexual production (males+females) was $0.18 \pm 0.03$ (26 


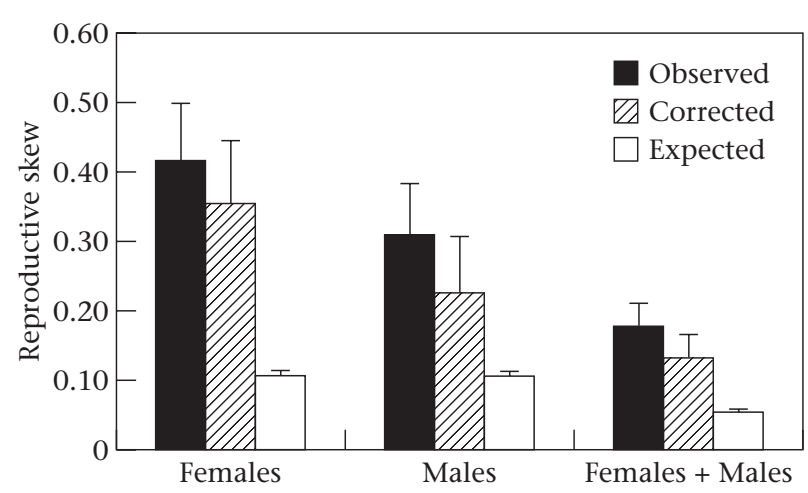

Figure 1. Mean+SD observed, corrected and expected reproductive skew for male, female and overall sexual production.

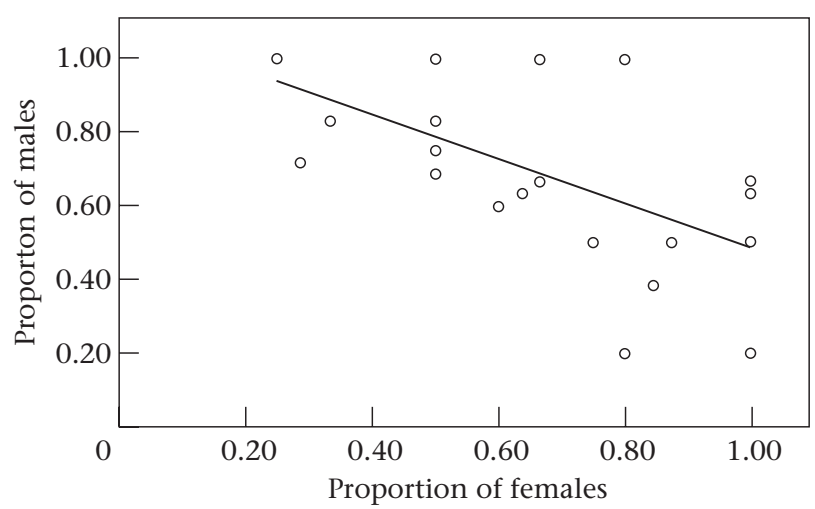

Figure 2. Relationship between the proportion of females and males produced by the most productive queen per colony.

colonies, range $0-0.64$; Fig. 1 ), a value again significantly higher than the expected value of $0.05 \pm 0.00$ (Wilcoxon signed-ranks test: $Z=-3.696, N=26, P<0.001)$.

Computation of the corrected skew (correcting for sampling errors) also indicates that, overall, skew was higher than expected under equal queen contribution. Inspection of Fig. 1 also suggests that skew was highest for female production, intermediate for male production and lowest for overall sexual production. The lower skew for overall sexual production could be explained if queens with a higher than average contribution to female production tend to produce fewer males. To test whether there is such a trade-off in male versus female production, we compared the relative contribution of the most productive queen (overall sexual production) to male and female production within each colony (Fig. 2). The proportions of males and females produced were significantly negatively correlated (Pearson: $r_{24}=-0.652$, $P<0.001)$, showing that there is indeed a trade-off between a queen's contribution to male and female production.

The observed skew was significantly negatively correlated with overall productivity (number of sexuals produced: Pearson: $\left.r_{24}=-0.441, P=0.024\right)$. However, the expected skew was also significantly negatively correlated with overall productivity (Pearson: $r_{24}=-0.963, P<0.001$ ) and, although steeper, the slope of the observed skew was not significantly different from the slope of the expected skew ( $t$ test: $t_{24}=-1.818, P=0.081$ ). The tendency for skew to be lower with higher productivity was also found using the modified B index with, in that case, a significant negative association (Spearman rank correlation: $\left.r_{\mathrm{S}}=-0.448, \quad N=26, P=0.021\right)$. Overall, these analyses indicate that there is no, or most probably a negative, correlation between skew and productivity.

\section{DISCUSSION}

Our data show that, although all queens contributed to male and female sexual production, they differed in their relative contribution in a significant proportion of colonies. Across colonies, reproductive skew was significant both for female and overall sexual production and close to significant for male production.

When sampling errors are taken into account, the corrected skew values for female, male and overall sexual production are $0.37 \pm 0.09,0.23 \pm 0.08$ and $0.12 \pm 0.03$, respectively. These values are higher than the value for egg production (corrected skew $=0.02$; calculated from the original data of Keller 1988), suggesting that there is higher skew for sexual than egg production in the Argentine ant. This could arise if some queens produce eggs that are more likely to develop into female sexuals than workers, as occurs in the fire ant S. invicta (Ross 1988). Differential contribution of queens could also arise if some queens produce a greater proportion of haploid eggs (which can develop only into males) than others. Argentine ant queens produce a significant number of haploid eggs; this proportion varies throughout the year (Aron et al. 1994) and is higher in polygynous than monogynous colonies (Keller et al. 1996). However, the latter study failed to show a significant difference between queens in the proportion of haploid eggs laid. This might be due to a lack of statistical power, owing to the relatively small number of eggs sexed, or a genuinely low variance among queens in the primary sex ratio laid. A similar study in monogynous colonies of fire ants showed that queens did vary in the proportion of haploid eggs laid (Aron et al. 1995). Thus, it is possible that differences in the relative contribution of queens to male production stems from differences in the number of male eggs produced in Argentine ants.

Although there was a significant reproductive skew, the overall reproductive skew was relatively low. This accords well with predictions of concession models (Keller \& Reeve 1994). These models predict low skew in L. humile, because relatedness between queens is low and ecological constraints on dispersal are weak or nonexistent (see Introduction). By contrast, low reproductive skew in L. humile does not accord well with the restraint models which would tend to predict high skew given the low relatedness and weak ecological constraints (Johnstone \& Cant 1999). Finally, tug-of-war models (Reeve et al. 1998) do not make clear predictions about expected skew because the expected value depends critically on the relative ability of queens to influence each other's reproduction and how such selfish efforts affect colony productivity. In this respect, it is important to note that aggressive interactions between queens have never been 
observed in Argentine ants (Keller \& Vargo 1993), suggesting that queens do not attempt to decrease each other's reproductive output directly. Hence, the most basic assumption of tug-of-war models is probably not fulfilled in L. humile.

Our analyses indicate that there was either no association or a negative correlation between colony productivity (measured as the number of sexuals that were produced and mated successfully) and reproductive skew. It is currently not possible to determine which of the two methods used is best suited to determine an association between skew and productivity. More studies and simulations are necessary to determine the most appropriate method to test for an association between productivity and skew. In any case both analyses suggest a negative association (significant in one case only), which contrasts with the prediction of concession models that higher group productivity should be associated with higher skew. However, the relationship between these two variables depends on the relatedness values and ecological constraints on dispersal. If relatedness is low and ecological constraints weak (as is apparently the case in the Argentine ant), low skew might be the stable condition, whatever the expected productivity of a two-queen association compared with a single queen colony.

Although the observed reproductive skew and behavioural interactions between L. humile queens are most consistent with the assumptions and predictions of concession models compared with those of other reproductive skew models, this does not mean that all the assumptions of the concession model are fulfilled. In particular, it is unclear whether increased queen number translates directly into greater colony productivity. In the Argentine ant, colony productivity depends mostly on the number of workers and there are no data showing that increased queen number increases colony productivity. In polygynous ants, increased queen number may have a positive indirect effect on colony productivity if it decreases the risk of colony extinction after the queen's death (Bourke \& Heinze 1994). However, it is unlikely that this argument applies to introduced colonies of Argentine ants, because queenless colonies may readily recruit queens from adjacent colonies. Hence, more data are needed to test whether the assumptions of concession models are really met in the Argentine ant.

An additional finding of our study was that there was a negative relationship between the relative contribution of queens to male and female production. The most likely explanation for this finding is that queens differ in the proportion of haploid and diploid eggs they lay. Thus, queens that lay more haploid eggs would contribute more to male production but less to female production. A previous study showed that queens lay different proportions of haploid eggs throughout the year (Aron et al. 1994). Furthermore, queens can alter the primary sex ratio in response to their social environment (Keller et al. 1996). However, as mentioned above, we did not detect any significant differences between queens in the proportion of haploid eggs laid. Thus, it remains to be investigated whether queens from the same colony differ in the primary sex ratio and whether such differences are responsible for the negative correlation between their relative contribution to male and female sexual production.

It is important to note that all colonies in our experiments contained two reproductive queens. There is currently no information on whether variation in queen numbers influences the variance in maternity between queens. This could be tested by creating colonies with variable queen number and determining how reproductive skew correlates with the number of queens per colony.

A direct consequence of the negative relationship between the relative contribution of queens to male and female production is a decrease in the probability of inbreeding. In the Argentine ant, the majority of sexuals mate in their parental nest and they do not discriminate against kin (Keller \& Fournier, in press). Thus, the tendency of queens to produce more individuals of one sex than the other should, everything else being equal, tend to decrease the probability of sib mating and inbreeding.

In conclusion, this study shows that there is a relatively low but significant reproductive skew for sexual production in the Argentine ant. Reproductive skew for sexual production was higher than for egg production, indicating that caution is needed when assessing skew from relative egg production by queens. In addition, there was a negative relationship between the contribution of queens to male and female sexual production. To our knowledge this is the first time that the existence of such a trade-off has been demonstrated and more studies will be necessary to determine whether this is a common pattern in haplodiploid social Hymenoptera.

\section{Acknowledgments}

We thank Catherine Roger for technical assistance Michel Chapuisat, Sara Helms Cahan, Peter Nonacs and two referees for their helpful comments on the manuscript. This research was supported by several grants from the Swiss NSF.

\section{References}

Aron, S., Passera, L. \& Keller, L. 1994. Queen-worker conflict over sex ratio: a comparison of primary and secondary sex ratios in the Argentine ant, Iridomyrmex humilis. Journal of Evolutionary Biology, 7, 403-418.

Aron, S., Vargo, E. L. \& Passera, L. 1995. Primary and secondary sex ratios in monogyne colonies of the fire ant Solenopsis invicta. Animal Behaviour, 49, 749-757.

Bourke, A. F. G. \& Franks, N. R. 1995. Social Evolution in Ants. Princeton, New Jersey: Princeton University Press.

Bourke, A. F. G. \& Heinze, J. 1994. The ecology of communal breeding: the case of multiple-queen leptothoracine ants. Philosophical Transactions of the Royal Society of London, Series B, 345, 359-372.

Bourke, A. F. G., Green, H. A. A. \& Bruford, M. W. 1997. Parentage, reproductive skew and queen turnover in a multiplequeen ant analysed with microsatellites. Proceedings of the Royal Society of London, Series B, 264, 277-283.

Chapuisat, M. \& Keller, L. 1999. Extended family structure in the ant Formica paralugubris: the role of the breeding system. Behavioral Ecology and Sociobiology, 46, 405-412. 
Chapuisat, M., Goudet, J. \& Keller, L. 1997. Microsatellites reveal high population viscosity and limited dispersal in the ant Formica paralugubris. Evolution, 51, 475-482.

Clutton-Brock, T. H., Brotherton, P. N. M., Russell, A. F., O'Riain, M. J., Gaynor, D., Kansky, R., Griffin, A., Manser, M., Sharpe, L., Mcllrath, G. M., Small, T., Moss, A. \& Monfort, S. 2001. Cooperation, control, and concession in meerkat groups. Science, 291, 478-481.

Emlen, S. T. 1982. The evolution of helping. II. The role of behavioral conflict. American Naturalist, 119, 40-53.

Heinze, J. 1995. Reproductive skew and genetic relatedness in Leptothorax ants. Proceedings of the Royal Society of London, Series B, 261, 375-379.

Johnstone, R. A. 2000. Models of reproductive skew: a review and synthesis. Ethology, 106, 5-26.

Johnstone, R. A. \& Cant, M. A. 1999. Reproductive skew and the threat of eviction: a new perspective. Proceedings of the Royal Society of London, Series B, 266, 275-279.

Keller, L. 1988. Evolutionary implications of polygyny in the Argentine ant, Iridomyrmex humilis (Mayr) (Hymenoptera: Formicidae): an experimental study. Animal Behaviour, 36, 159-165.

Keller, L. 1995. Social life: the paradox of multiple-queen colonies. Trends in Ecology and Evolution, 10, 355-360.

Keller, L. \& Fournier, D. In press. Lack of inbreeding avoidance in the Argentine ant Linepithema humile. Behavioral Ecology.

Keller, L. \& Krieger, M. J. B. 1996. Mating success of male birds. Nature, 380, 208-209.

Keller, L. \& Passera, L. 1989. Influence of the number of queens on nestmate recognition and attractiveness of queens to workers in the Argentine ant Iridomyrmex humilis (Mayr). Animal Behaviour, 37, 733-740.

Keller, L. \& Passera, L. 1992. Mating system, optimal number of matings, and sperm transfer in the Argentine ant Iridomyrmex humilis. Behavioral Ecology and Sociobiology, 31, 359-366.

Keller, L. \& Passera, L. 1993. Incest avoidance, fluctuating asymmetry, and the consequences of inbreeding in Iridomyrmex humilis, an ant with multiple queen colonies. Behavioral Ecology and Sociobiology, 33, 191-199.

Keller, L. \& Reeve, H. K. 1994. Partitioning of reproduction in animal societies. Trends in Ecology and Evolution, 9, 98-102.

Keller, L. \& Vargo, E. L. 1993. Reproductive structure and reproductive roles in colonies of eusocial insects. In: Queen Number and Sociality in Insects (Ed. by L. Keller), pp. 16-44. Oxford: Oxford University Press.

Keller, L., L'Hoste, G., Balloux, F. \& Plumey, O. 1996. Queen number influences the primary sex ratio in the Argentine ant, Linepithema humile (=Iridomyrmex humilis). Animal Behaviour, 51, 445-449.

Kokko, H., Mackenzie, A., Reynolds, J. D., Lindström, J. \& Sutherland, W. J. 1999. Measures of inequality are not equal. American Naturalist, 154, 358-382.

Krieger, M. J. B. \& Keller, L. 1999. Low polymorphism at 19 microsatellite loci in a French population of Argentine ants (Linepithema humile). Molecular Ecology, 8, 1078-1080.

Krieger, M. J. B. \& Keller, L. 2000. Mating frequency and genetic structure of the Argentine ant Linepithema humile. Molecular Ecology, 9, 119-126.

Markin, G. P. 1970. The seasonal life cycle of the Argentine ant, Iridomyrmex humilis (Hymenoptera, Formicidae), in southern
California. Annals of the Entomological Society of America, 63, 1238-1242.

Newell, W. 1909. The life history of the Argentine ant. Journal of Economic Entomology, 2, 174-192.

Nonacs, P. 2000. Measuring and using skew in the study of social behavior and evolution. American Naturalist, 156, 577-589.

Passera, L. \& Keller, L. 1992. The period of sexual maturation and the age at mating in Iridomyrmex humilis, an ant with intranidal mating. Journal of Zoology, London, 228, 141-153.

Queller, D. C. \& Goodnight, K. F. 1989. Estimating relatedness using genetic markers. Evolution, 43, 258-275.

Ragsdale, J. E. 1999. Reproductive skew theory extended: the effect of resource inheritance on social organization. Evolutionary Ecology Research, 1, 859-874.

Reeve, H. K. 1998. Game theory, reproductive skew, and nepotism. In: Game Theory and Animal Behavior (Ed. by L. Dugatkin \& H. K. Reeve), pp. 118-145. New York: Oxford University Press.

Reeve, H. K. \& Emlen, S. T. 2000. Reproductive skew and group size: an N-person staying incentive model. Behavioral Ecology, 11, 640-647.

Reeve, H. K. \& Keller, L. 1997. Reproductive bribing and policing as evolutionary mechanisms for the suppression of within-group selfishness. American Naturalist, 150, S42-S58.

Reeve, H. K. \& Keller, L. 2001. Tests of reproductive-skew models in social insects. Annual Review of Entomology, 46, 343-385.

Reeve, H. K. \& Ratnieks, F. L. W. 1993. Queen-queen conflicts in polygynous societies: mutual tolerance and reproductive skew. In: Queen Number and Sociality in Insects (Ed. by L. Keller), pp. 45-85. Oxford: Oxford University Press.

Reeve, H. K., Emlen, S. T. \& Keller, L. 1998. Reproductive sharing in animal societies: reproductive incentives or incomplete control by dominant breeders. Behavioral Ecology, 9, 267-278.

Reeve, H. K., Starks, P. T., Peters, J. M. \& Nonacs, P. 2000. Genetic support for the evolutionary theory of reproductive transactions in social wasps. Proceedings of the Royal Society of London, Series B, 267, 75-79.

Reuter, M., Balloux, F., Lehmann, L. \& Keller, L. In press. Kin structure and queen execution in the Argentine ant Linepithema humile. Journal of Evolutionary Biology.

Rice, W. 1989. Analyzing tables of statistical tests. Evolution, 43, 223-225.

Ross, K. G. 1988. Differential reproduction in multiple-queen colonies of the fire ant Solenopsis invicta (Hymenoptera: Formicidae). Behavioral Ecology and Sociobiology, 23, 341-355.

Sokal, R. R. \& Rohlf, F. J. 1995. Biometry. The Principles and Practice of Statistics in Biological Research. 3rd edn. San Francisco: W. H. Freeman.

Stille, M. \& Stille, B. 1992. Intra- and inter-nest variation in mitochondrial DNA in the polygynous ant Leptothorax acervorum (Hymenoptera: Formicidae). Insectes Sociaux, 39, 335-340.

Stuart, R. J., Gresham-Bissett, L. \& Alloway, T. M. 1993. Queen adoption in the polygynous and polydomous ant, Leptothorax curvispinosus. Behavioral Ecology, 4, 276-281.

Tsuji, K. \& Tsuji, N. 1998. Indices of reproductive skew depend on average reproductive success. Evolutionary Ecology, 12, 141-152.

Vehrencamp, S. L. 1983a. A model for the evolution of despotic versus egalitarian societies. Animal Behaviour, 31, 667-682.

Vehrencamp, S. L. 1983b. Optimal degree of skew in cooperative societies. American Zoologist, 23, 327-335. 